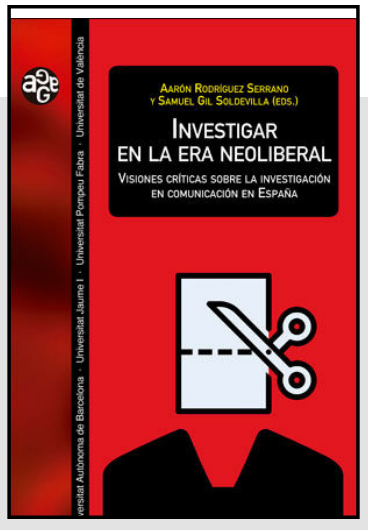

Investigar en la era neoliberal. Visiones críticas sobre la investigación en comunicación en España Aarón Rodríguez Serrano y Samuel Gil Soldevilla Universitat Autònoma De Barcelona, Barcelona, 2018

\title{
Investigar en la era neoliberal. Visiones críticas sobre la investigación en comunicación en España
}

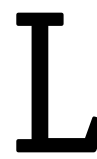

a educación universitaria en España ha sufrido modificaciones en su modelo como consecuencia de las reformas políticas y de la incorporación de ésta al Espacio Europeo de Educación Superior a través del conocido plan Bolonia. Asimismo, la crisis del 2008 ha provocado la reducción de ayudas y la precarización del docente-investigador viéndose también afectados los estudios de comunicación. El interés actual de la Universidad gira en el ámbito económico-empresarial y gubernamental priorizando la obtención de recursos económicos, frente al conocimiento científico.

Por otro lado, el capitalismo académico impera en la esfera universitaria. Se implanta un modelo basado en la publicación de artículos con una visión unidireccional del saber, provocando una mercantilización del conocimiento, priorizando dichas publicaciones frente al avance en los diferentes campos de la investigación en comunicación.

A partir de este contexto, el libro plantea cómo se ha instaurado un modelo de publicación estandarizando, no real y poco innovador, que incluye a la comunica- 
ción dentro de las Ciencias Sociales. Un procedimiento caracterizado por las métricas que miden el impacto de los artículos y de las revistas, con el que se elaboran índices y rankings internacionales encargados de posicionar la excelencia de los docentes y universidades. Las agencias encargadas de elaborar estas listas siguen un sistema utilitarista en el que prima la producción y rendimiento científico del investigador, dejando en segundo plano al conocimiento.

Este modelo culmina con el triunfo del paper y el formato IMRyD como medio de comunicación, dejando de lado al resto de formatos en los procesos de acreditación de la actividad científica, reduciendo así la capacidad creativa y artística del contenido.

Un modelo editorial que condiciona todo el sistema de publicación, basado en la oferta y la demanda, constituido alrededor de las editoriales mejor posicionadas en los rankings internacionales, donde se priorizan posiciones mercantiles frente a intereses investigadores.

A nivel internacional no existe un sistema unificado para evaluar la actividad investigadora. En España, la Agencia Nacional de Evaluación de la Calidad y Acreditación junto con la Comisión Nacional Evaluadora de la Actividad Investigadora son los organismos encargados de evaluar y reconocer la trayectoria científica, y expedir acreditaciones a los investigadores. Los procedimientos de acreditación y evaluación se rigen por una legislación complicada y convocatorias enrevesadas en las que se agrupan las disciplinas y se reduce la valoración de la actividad científica a las publicaciones en revistas de alto impacto, dificultando el proceso de acreditación y evaluación. Esto, a juicio de los autores, tiene como consecuencia, aunque sea de forma indirecta, que el sistema condiciona gravemente la actividad y libertad investigadora, perjudicando a las Ciencias de la Comunicación, ya que los investigadores priorizan en sus estudios temas de interés editorial.

La agrupación por equipos de investigación cada vez es más frecuente. La investigación colaborativa permite mayor eficacia y rapidez. Sin embargo, se instaura un clima de competencia y rivalidad entre grupos de investigación por optar a proyectos de investigación. 
El texto revela que el sistema de investigación fuera de la frontera española es diferente, la influencia en el paradigma internacional fluctúa entre Estados Unidos y Reino Unido, lo que implica que es necesario adaptarse a la estructura que imponen para no quedar excluido del sistema.

Ante esta situación desoladora, los autores plantean que es necesario aprovechar las ventajas que ofrece la digitalización y el desarrollo tecnológico para promover un conocimiento abierto, transparente, compartido y crítico. La creación de una comunicología abierta puede suponer el avance conjunto hacia una sociedad cognitiva donde la mercantilización desaparezca y prime la búsqueda ética de conocimiento, creando espacios comunes que integren valores multiculturales adaptados a la sociedad actual.

\section{Alejandro Carbonell-Alcocer \\ Investigador Predoctoral Universidad Rey Juan Carlos (URJC) http://orcid.org/0000-0003-0081-4728 \\ España}

\section{(c) (1) (9)}

Esta obra está bajo una licencia de Creative Commons Reconocimiento-NoComercial 4.0 Internacional. 